\title{
The Concealed Fact: Relationship of Healthcare Performance and Income Inequality in the United States Based on Factor Analysis
}

\author{
Xuchen Jiang, a, Jia Liu ${ }^{2, \text { b, }}$ Yupei Sun ${ }^{3, \text { c, }}$ Xiaoke Wang ${ }^{4, d}$ \\ ${ }^{1}$ School of Economics, Shandong University, Jinan, Shandong 250100, China \\ ${ }^{2}$ No.7 Middle School of Zhengzhou, Henan, China \\ ${ }^{3}$ Shanghai World Foreign Language Academy, China \\ ${ }^{4}$ International Department of Chengdu Shude High School, Sichuan, China \\ a201900011016@mail.sdu.edu.cn, b2484796850@qq.com, ${ }^{c}$ sunyupei@qq.com, ${ }^{d} 1275335264 @ q q . c o m$. \\ These authors contributed equally.
}

\begin{abstract}
Healthcare is a public program that combines the endeavour from aspects like the government and healthcare suppliers. To address the issue of healthcare's unequal distribution caused by the income gap and improve the outcomes of policy design and public administration, the research is conducted in favour of factor analysis to build a connection between the two key factors. Utilizing this relationship, the fact will illustrate how the underlying machinery goes in the healthcare system, which can help the policymakers efficiently address problems like short life expectancy and relatively high mortality rate faced with the poor populations.
\end{abstract}

Keywords: Healthcare, income inequality, Gini coefficient, factor analysis

\section{INTRODUCTION}

Considered a basic human right, healthcare is a critical approach and a crucial system to guarantee the quality and dignity of life among the whole population[1]. Unfortunately, because of factors like imbalanced development and regional poverty caused by the side effects of globalization, the quality of healthcare has several determining factors that can be very complicated to handle, resulting in the terrible functioning of the healthcare resources [2]. Among them, the foremost issue is that income inequality exerts a negative effect on healthcare. A number of research have shown that higher income inequality is associated with the poorer overall health of the population [3].

This research investigates and analyzes how income inequality can influence healthcare in the United States through the years from 1980 to 2017. To make it clearer, it is of great significance to define the core meaning of healthcare first. Different from the word "health", which means a state of complete physical, mental and social well-being and not merely the absence of disease or infirmity, healthcare emphasizes more on the set of services provided by a country or an organization for the treatment of the physically and the mentally ill [4]. It includes maintaining and improving the health of residents through systematic procedures like prevention, diagnose and treatment. Compared with the medicallikely definition of health, it can be concluded that healthcare is more likely to react with the professional insights about social science like economics and politics.

This paper uses the United States as the target country to focus on since it is the most powerful developed country with great healthcare representation. However, the current situation is that the U.S. faces a severe challenge of healthcare inequality [5] caused by increasing income inequality [6]. A theoretical development has also revealed that income inequality in the U.S. caused severe harm to healthcare, which provoked the policymakers and scholars to concern about the situation in reality [7]. By selecting the U.S., we can develop a comprehensive insight into the conflict and relationship between healthcare and income, providing a bunch of systematic and feasible lessons to help improve the public policy-making in developed countries and emerging economies [8].

It is important to build a thorough measuring system to evaluate the comprehensive organization of healthcare 
since healthcare is a complicated existence, including many dimensions such as expenditure, accessibility, and target [9] that cannot be surveyed directly. This paper evaluates the U.S. healthcare system from three perspectives: structure, process, and outcomes [10]. Specifically, the number of hospital beds and physicians was chosen as indicators of the health care system structure; mortality and life expectancy were used as outcome measures. Annual income parity is measured by the Gini coefficient, which is an internationally accepted measure of income disparity between residents of a country or region.

Then, it is also clear that this research will build a logical connection between income and the measuring system to figure out the exact relationship between income inequality and healthcare inequality.

In addition, not enough previous research has focused on issues as follow:

Previous research has used standardized indexes such as mortality and life expectancy in the United States [11, 12] and adjusted Net Promoter Score (NPS)[13]. However, nearly all the standards were used separately or incompletely, and factor like the vaccination rate of one certain disease was sometimes ignored. Thus, a more profound and exhaustive system based on factors like the outcome, process, and structure needs to be constructed for this issue.

One of the past research outlines the potential mechanisms underlying the so-called relative income hypothesis, which predicts that an individual's health status is better in societies with an equal distribution of incomes [14]. However, based on our research on the US healthcare system and income inequality through chronological order, this hypothesis does not effectively describe the current situation in the United States.

In this paper, six indicators such as mortality, life expectancy, and other indicators in the United States are first found in chronological order with the Gini coefficient for each year during 1980-2017. A model is built using factor analysis method and regression to combine the correlation between income disparity and the healthcare system. Finally, the correlation between them and the influence of some other possible variables are discussed. The predicted result is that despite the increase in income inequality in the United States, its healthcare system is gradually getting better, resulting in better overall health of the U.S. residents and worse health situations for the poor.

\section{DATAS AND METHODS}

\subsection{Method}

To evaluate the quality of healthcare in the United States more precisely, this research plans to build an indicator system that can reflect healthcare performance with the method of factor analysis. The indicator system will develop as a time-series analysis of the healthcare in the U.S. from 1980-2017, which means every year will be given an evaluating score to show its quality. Ultimately, to figure out the underlying relationship between healthcare quality and income inequality, the score sequence will be associated with the Gini coefficient every year from 1980-2017 using the method of unary linear regression.

The method of factor analysis is a statistical method used to describe variability among observed, correlated variables in terms of a potentially lower number of unobserved variables called factors. The basic mathematical model of the method can be described as follows:

Set the research target as $\mathrm{P}$, and the observed variables that may have correlations with $\mathrm{P} X=\left(\mathrm{X}_{l}\right.$, $\left.\mathrm{X}_{2}, \mathrm{X}_{3}, \ldots, \mathrm{X}_{p}\right)$. The mean vector of $\mathrm{P}$ is $\mathrm{E}(\mathrm{X})=0, \mathrm{X}_{p}$ is the information of the original variable. Set $\mathrm{F}=\left(\mathrm{F}_{1}, \mathrm{~F}_{2}, \mathrm{~F}_{3}, \ldots, \mathrm{X}_{m}\right)$ as the new factor variable information that $P$ extracts, and $\mathrm{m} \leqq \mathrm{p}$, the mean vector of $\mathrm{F}$ is $\mathrm{E}(\mathrm{F})=0$. Also, the $\mathrm{X} i$ has a special factor $g_{i}(\mathrm{i}=1,2, \ldots, \mathrm{p})$; $\mathrm{g}=\left(g_{1}, g_{2}, g_{3}, \ldots, g_{p}\right)$ stands for the remaining information that the new factor variables extracted from the original variables cannot express. The functions below show the linear relationship among the three of them(Guo,2020).

$$
\left\{\begin{array}{c}
X_{1}=a_{11} F_{1}+a_{12} F_{12}+\ldots+a_{1 m} F_{m}+g_{1} \\
X_{2}=a_{21} F_{1}+a_{22} F_{12}+\cdots+a_{2 m} F_{m}+g_{2} \\
X_{p}=a_{p 1} F_{1}+a_{p 2} F_{12}+\ldots+a_{p m} F_{m}+g_{p}
\end{array}\right.
$$

The system will include three main sectors: the structure indicators, the process indicators, and the outcome indicators. The structure indicator consists of two factors: the number of medical beds per 1000 people and the number of physicians per 1000 people. These two factors will illustrate the supply structure of the real situation in the healthcare system of the U.S. The process indicator includes the vaccination rates of measles and DPT in people aged from 12 months to 23 months. These two factors can be ideal standards for this research to figure out whether healthcare in the U.S. can function well in the process of enhancing public health by preventing or healing civics' diseases. Last, the outcome indicator comprises the rough mortality rate in 1000 people and the life expectancy at birth. The two factors aim to represent the results of the implementation of healthcare in the U.S. 
Table1 the summary of the evaluation system

\begin{tabular}{|c|c|c|c|}
\hline Indicator & Factors & Code & Category \\
\hline \multirow[t]{2}{*}{ Structure } & The number of medical beds & $\mathrm{E}$ & Positive \\
\hline & The number of physicians & $\mathrm{F}$ & Positive \\
\hline \multirow[t]{2}{*}{ Process } & $\begin{array}{c}\text { The vaccination rate of } \\
\text { measles }\end{array}$ & G & Positive \\
\hline & The vaccination rate of DPT & $\mathrm{H}$ & Positive \\
\hline \multirow[t]{2}{*}{ Outcome } & The rough mortality rate & $\mathrm{C}$ & Negative \\
\hline & The life expectancy at birth & $\mathrm{B}$ & Positive \\
\hline
\end{tabular}

According to the table above, the research has set up an indicator system to rank the healthcare of the U.S. Among the three sectors and 6 factors, only the rough mortality $(C)$ rate remains a position of the negative factor, which means that the higher the F factor holds, the worse the healthcare system will be. On the contrary, healthcare will be better if the positive factors of B, E, F, G, and $\mathrm{H}$ are greater.

Utilizing the evaluation system, the research can get the specific scores of the healthcare each year from 1980 to 2017. It is of significance to combine the score with the Gini coefficient, which can be a very clear indicator of income inequality. This article researches by selecting the method of unary linear regression. The basic mathematical model of the method can be described as follows:

The unary linear regression analysis establishes a linear regression equation of $\mathrm{x}$ and $\mathrm{Y}$ for prediction based on the correlation between the independent variable $\mathrm{x}$ and the dependent variable Y. The prediction model of unary linear regression is:

$$
Y_{t}=a x_{t}+b
$$

In the model, $x_{t}$ represents the value of the independent variable in period $t$, and $Y_{t}$ represents the value of the dependent variable in period $t$. What is more, $a$ and $b$ represent the parameters of the unary linear regression equation. The value of $\mathrm{a}$ and $\mathrm{b}$ can be calculated as follow:

$$
\left\{\begin{array}{l}
\mathrm{b}=\frac{\sum \mathrm{Y}_{\mathrm{i}}}{\mathrm{n}}-\mathrm{a} \frac{\sum \mathrm{x}_{\mathrm{i}}}{\mathrm{n}} \\
a=\frac{n \sum \boldsymbol{x}_{\boldsymbol{i}} \boldsymbol{Y}_{i}-\sum \boldsymbol{x}_{\boldsymbol{i}} \sum \boldsymbol{Y}_{\boldsymbol{i}}}{\boldsymbol{n} \sum \boldsymbol{x}_{i}^{2}-\left(\sum \boldsymbol{x}_{i}\right)^{2}}
\end{array}\right.
$$

\subsection{Data}

The research accessed the data about the Gini coefficient from the Census Bureau of the United States database. The rest of the data were retrieved from the database at World Bank. A reliable conclusion cannot be drawn without turning the negative factor into a positive one. Therefore, the research selects the following formula to guarantee the survey's feasibility:

$$
D=C_{i}^{\prime}=\frac{1}{C_{i}}
$$

This formula means that the research will process the data about the rough mortality rate per 1000 people, coded as $C$, by setting the reciprocal of $C_{i}$ as $D\left(D=C_{i}^{\prime}\right)$. During the whole article, the $\mathrm{D}$ will function as the right variable. 
Table 2 The summary of data

\begin{tabular}{|c|c|c|c|c|c|c|c|c|}
\hline time & $\operatorname{life}(B)$ & mortality $(C)$ & $\begin{array}{l}1 / \text { mortality } \\
\text { (D) }\end{array}$ & $\operatorname{bed}(E)$ & physician(F) & measles(G) & DPT(H) & Gini \\
\hline 1980 & 73.60976 & 8.8 & 0.113636 & 6 & 1.5 & 86 & 96 & 0.403 \\
\hline 1981 & 74.00976 & 8.6 & 0.116279 & 5.9 & 1.5 & 97 & 96 & 0.406 \\
\hline 1982 & 74.36098 & 8.5 & 0.117647 & 5.9 & 1.6 & 97 & 96 & 0.412 \\
\hline 1983 & 74.46341 & 8.6 & 0.116279 & 5.8 & 1.6 & 98 & 97 & 0.414 \\
\hline 1984 & 74.56341 & 8.7 & 0.114943 & 5.7 & & 98 & 97 & 0.415 \\
\hline 1985 & 74.56341 & 8.7 & 0.114943 & 5.5 & & 97 & 96 & 0.419 \\
\hline 1986 & 74.61463 & 8.7 & 0.114943 & 5.4 & 1.7 & 97 & 97 & 0.425 \\
\hline 1987 & 74.76585 & 8.6 & 0.116279 & 5.2 & 1.8 & 82 & 97 & 0.426 \\
\hline 1988 & 74.76585 & 8.9 & 0.11236 & 5.1 & 1.8 & 98 & 97 & 0.426 \\
\hline 1989 & 75.01707 & 8.8 & 0.113636 & 5 & 1.8 & 94 & 94 & 0.431 \\
\hline 1990 & 75.21463 & 8.6 & 0.116279 & 4.9 & 1.8 & 90 & 90 & 0.428 \\
\hline 1991 & 75.36585 & 8.6 & 0.116279 & 4.8 & 1.9 & 87 & 86 & 0.428 \\
\hline 1992 & 75.61707 & 8.5 & 0.117647 & 4.6 & 1.9 & 83 & 83 & 0.433 \\
\hline 1993 & 75.41951 & 8.8 & 0.113636 & 4.5 & 1.9 & 84 & 88 & 0.454 \\
\hline 1994 & 75.61951 & 8.8 & 0.113636 & 4.3 & & 89 & 94 & 0.456 \\
\hline 1995 & 75.62195 & 8.8 & 0.113636 & 4.1 & 2.4385 & 88 & 95 & 0.45 \\
\hline 1996 & 76.02683 & 8.8 & 0.113636 & 3.9 & 2 & 91 & 95 & 0.455 \\
\hline 1997 & 76.42927 & 8.7 & 0.114943 & 3.8 & 2.1 & 91 & 96 & 0.459 \\
\hline 1998 & 76.58049 & 8.6 & 0.116279 & 3.7 & 2.1 & 92 & 96 & 0.456 \\
\hline 1999 & 76.58293 & 8.6 & 0.116279 & 3.6 & 2.2 & 92 & 96 & 0.458 \\
\hline 2000 & 76.63659 & 8.5 & 0.117647 & 3.49 & 2.5942 & 91 & 94 & 0.462 \\
\hline 2001 & 76.83659 & 8.5 & 0.117647 & 3.47 & 2.2 & 91 & 94 & 0.466 \\
\hline 2002 & 76.93659 & 8.5 & 0.117647 & 3.39 & 2.3 & 91 & 94 & 0.462 \\
\hline 2003 & 77.03659 & 8.4 & 0.119048 & 3.33 & & 93 & 96 & 0.464 \\
\hline 2004 & 77.4878 & 8.2 & 0.121951 & 3.26 & 2.7147 & 93 & 96 & 0.466 \\
\hline 2005 & 77.4878 & 8.3 & 0.120482 & 3.2 & 2.4356 & 92 & 96 & 0.469 \\
\hline 2006 & 77.6878 & 8.1 & 0.123457 & 3.18 & 2.4285 & 92 & 96 & 0.47 \\
\hline 2007 & 77.9878 & 8 & 0.125 & 3.14 & 2.4358 & 92 & 96 & 0.463 \\
\hline 2008 & 78.03902 & 8.1 & 0.123457 & 3.13 & 2.4412 & 92 & 96 & 0.466 \\
\hline 2009 & 78.39024 & 7.9 & 0.126582 & 3.08 & 2.4471 & 90 & 95 & 0.468 \\
\hline 2010 & 78.54146 & 7.995 & 0.125078 & 3.05 & 2.4354 & 92 & 95 & 0.47 \\
\hline 2011 & 78.64146 & 8.073 & 0.12387 & 2.97 & 2.4641 & 92 & 96 & 0.477 \\
\hline 2012 & 78.74146 & 8.102 & 0.123426 & 2.93 & 2.4985 & 91 & 94 & 0.477 \\
\hline
\end{tabular}




\begin{tabular}{lllllllll}
\hline 2013 & 78.74146 & 8.215 & 0.121729 & 2.89 & 2.5596 & 92 & 94 & 0.482 \\
2014 & 78.84146 & 8.237 & 0.121403 & 2.83 & 2.574 & 92 & 95 & 0.48 \\
2015 & 78.69024 & 8.44 & 0.118483 & 2.8 & 2.5781 & 92 & 95 & 0.479 \\
2016 & 78.53902 & 8.493 & 0.117744 & 2.77 & 2.5881 & 92 & 95 & 0.481 \\
2017 & 78.53902 & 8.638 & 0.115768 & 2.87 & 2.612 & 92 & 95 & 0.489 \\
\hline
\end{tabular}

Source: World Bank \& The Census Bureau of the U.S[15]

Before starting, it is important to make a KMO test, which will show whether the research can be done through the method of factor analysis. According to Kaiser's theory [16], the effectiveness of KMO test is shown as follows:

Table 3 The KMO test

\begin{tabular}{cc}
\hline The value of KMO & $\begin{array}{c}\text { The effectiveness of } \\
\text { evaluation }\end{array}$ \\
\hline $0.00 \sim 0.49$ & Can not be accepted \\
$0.50 \sim 0.59$ & Very bad \\
$0.60 \sim 0.69$ & Can be accepted reluctantly \\
$0.80 \sim 0.89$ & Relatively good and can be \\
accepted \\
$0.90 \sim 1.00$
\end{tabular}

Source: Guo's article, 2020[17]

With the help of Stata15, the research successfully got the value of KMO test around 0.67, which can be located in the range of "can be accepted reluctantly". Under such a circumstance, the research can be conducted with the method of factor analysis.

Table 4 The process of factor extraction

\begin{tabular}{ccccc}
\hline Factor & Eigenvalue & Difference & Proportion & Cumulative \\
\hline Factor1 & 3.46204 & 1.88419 & 0.5770 & 0.5770 \\
Factor2 & 1.57786 & 1.09469 & 0.2630 & 0.8400 \\
Factor3 & 0.48316 & 0.08765 & 0.0805 & 0.9205 \\
Factor4 & 0.39551 & 0.33087 & 0.0659 & 0.9864 \\
Factor5 & 0.06464 & 0.04786 & 0.0108 & 0.9972 \\
Factor6 & 0.01678 & & 0.0028 & 1.000 \\
\hline
\end{tabular}

After confirming the validity of the data and the method, the research continues with Stata15 to extract factors with an eigenvalue above 1 . In this survey, two main factors are the ideal ones, and they are named after factor 1 and factor 2 . Among the 6 factors, factor 1 has an eigenvalue of 3.46204, which means this factor is the most influential factor when evaluating the healthcare system. Factor 2 has an eigenvalue of 1.57786 , and it is the second influential factor of evaluating the healthcare of the U.S. when factor 1 and factor 2 are uncorrelated. What is more, the cumulative contribution rate of the two factors reaches 0.84 , also presenting the fact that all the information about the original variables can be represented very well by the 2 factors.

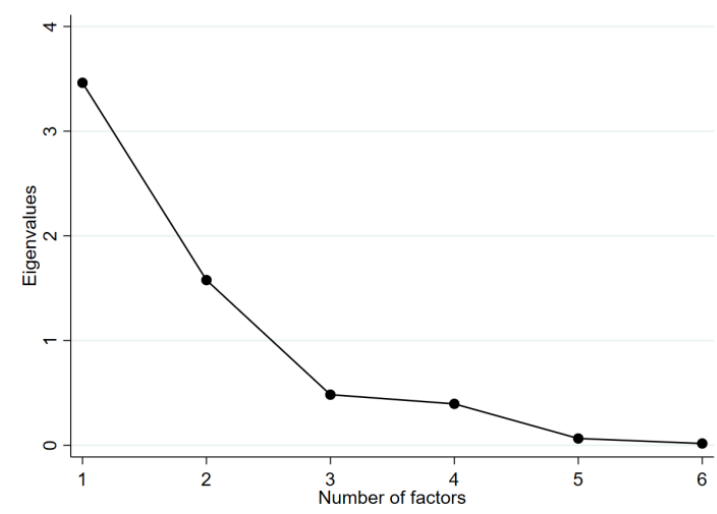

Figure 1 The scree plot of eigenvalues after factor

To be more detailed, the slopes of the first two factors are relatively bigger in the figure above, but the slopes of the rest of the factors are relatively smaller. This fact clearly explains that factor 1 and factor 2 make a greater contribution in illustration, especially compared with the factors from 3-6. This shows that it is very suitable to extract factors 1 and factor 2 .

Due to the complex relationship between the common and original variables, the research may have difficulty defining the correlation between one specific variable and each common factor [18]. Therefore, the research utilizes the rotation method in Stata15 to figure out the common factors and the exact meanings of each common factor.

Table 5 Rotated factor loadings (pattern matrix) and unique variances

\begin{tabular}{cccc}
\hline \multicolumn{1}{c}{ Variable } & Factor1 & Factor2 & Uniqueness \\
\hline B & 0.9825 & 0.0418 & 0.0329 \\
D & 0.7874 & 0.1108 & 0.3677 \\
E & -0.9696 & 0.0249 & 0.0593 \\
F & 0.9540 & 0.0099 & 0.0898 \\
G & -0.0548 & 0.8937 & 0.1983 \\
H & 0.1027 & 0.8817 & 0.2121 \\
\hline
\end{tabular}


Figure 3, factor 1 shows high positive correlations with variables $\mathrm{B}, \mathrm{D}$, and $\mathrm{F}$. At the same time, factor shows positive correlations with variables $\mathrm{E}, \mathrm{G}$, and $\mathrm{H}$. Recalling the respective meaning of the letter codes, the research names factor 1 after the human factor, which includes all the elements attached to human beings like life expectancy, rough mortality and the number of physicians. Similarly speaking, factor 2 can be named the object factor, which includes all the elements attached to physical issues like the number of medical beds and vaccination rates.

Set the human factor as $f$, the object factor as $f_{2}$, and the total score as $f$. The research calculates by summing the weights that are separately attached to $f 1$ or $f_{2}$. Clearly, the weights of each common factor are the variance proportion when extracting common factors. Thus, the ultimate formula of evaluation is drawn below:

$$
f=0.5749 * f 1+0.2651 * f 2
$$

The research can make a thorough ranking and give specific scores to the annual healthcare in the U.S. from 1980-2017. Concerning the lack of data, the years 1984 , 1985,1994 , and 2003 are eliminated in this period. The ranking result is shown in table 4 below. The research has found that the year 2011 is the best year in U.S. healthcare since 1980, and the worst one is 1992.

Table 6 The ultimate score of the healthcare

\begin{tabular}{ccc}
\hline year & score & rank \\
\hline 2011 & 0.758498 & 1 \\
2010 & 0.72124 & 2 \\
2014 & 0.706432 & 3 \\
2007 & 0.698768 & 4 \\
2009 & 0.69456 & 5 \\
2004 & 0.670101 & 6 \\
2008 & 0.65169 & 7 \\
2013 & 0.645963 & 8 \\
2012 & 0.643191 & 9 \\
2006 & 0.60454 & 10 \\
\hline
\end{tabular}

Table 7 data about the regression

\begin{tabular}{lllllll}
\hline $\mathrm{f}$ & Coef. & Std.Err. & $\mathrm{t}$ & $\mathrm{P}>|\mathrm{t}|$ & {$[95 \%$ Conf. Interval] } \\
& & & & & \\
\hline $\mathrm{I}$ & 21.94906 & 2.440005 & 9.00 & 0.000 & 16.9789326 .91919 \\
& & & & & \\
cons & -9.935822 & 1.106091 & -8.98 & 0.000 & -12.18886 & - \\
& & & & & 7.682788 \\
\hline
\end{tabular}

According to Figure 4, the equation can be drawn as follows:

\begin{tabular}{|c|c|c|}
\hline 2015 & 0.591806 & 11 \\
\hline 2016 & 0.558458 & 12 \\
\hline 2017 & 0.482633 & 13 \\
\hline 2005 & 0.477229 & 14 \\
\hline 2000 & 0.185436 & 15 \\
\hline 2002 & 0.108212 & 16 \\
\hline 1999 & 0.081716 & 17 \\
\hline 2001 & 0.045752 & 18 \\
\hline 1998 & 0.026088 & 19 \\
\hline 1997 & -0.08475 & 20 \\
\hline 1995 & -0.26301 & 21 \\
\hline 1996 & -0.27512 & 22 \\
\hline 1988 & -0.37014 & 23 \\
\hline 1986 & -0.40884 & 24 \\
\hline 1983 & -0.44018 & 25 \\
\hline 1982 & -0.49625 & 26 \\
\hline 1989 & -0.56172 & 27 \\
\hline 1981 & -0.62172 & 28 \\
\hline 1990 & -0.75708 & 29 \\
\hline 1987 & -0.77569 & 30 \\
\hline 1991 & -0.97809 & 31 \\
\hline 1993 & -1.02995 & 32 \\
\hline 1980 & -1.13761 & 33 \\
\hline 1992 & -1.15216 & 34 \\
\hline
\end{tabular}

The research aims to find out the effects that income inequality can have on healthcare. Thus, the last step in data processing is to make a unary linear regression between the Gini coefficient and the score f. Set Gini coefficient as I. Using the tool of Stata15, the regression can be finished quickly. 
The exact explanation of this equation is that 1 unit of increase in the Gini coefficient will lead to 21.94906 units of increase in the total score of the healthcare. Based on the data in this research, the explanation can also be drawn in the chart below.

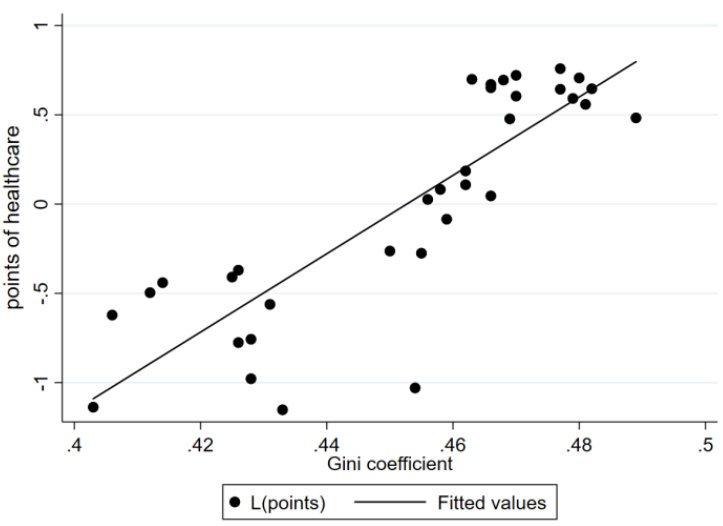

Figure 2 chart about the regression

This conclusion shows that the Gini coefficient shares a high positive correlation with the total score. It is also easy to know that this equation meets the requirement of the residual test, which means the following three equations establish at the same time. $\sum \hat{u}_{i}=0$

$$
\begin{aligned}
& \sum \hat{u}_{i}=0 \\
& \sum x_{i} \hat{u}_{i}=0 \\
& \sum \hat{y}_{i} \hat{u}_{i}=0
\end{aligned}
$$

According to Figure 4, the modulus of $t$ is greater than 2.58 , which means that the explanation model is obvious and valid at the significance level of $99 \%$.

\section{DISCUSSION and EVALUATION}

\subsection{Discussion}

The essay demonstrates that the Level of healthcare has a positive correlation with the Gini coefficient when a regression is done regarding them. It is commonly perceived that a larger Gini coefficient indicates a higher level of income inequality and is regarded as negative to society. However, surprisingly, it has been found out that it has a positive correlation with the level of healthcare. A possible explanation for that is that the high Gini coefficient actually causes a higher level of total GDP in lots of cases. Countries with a low Gini coefficient usually apply policies to reduce the gap between the rich and the poor, such as universal basic income, high unemployment benefit, transfer payment, highly progressive income tax, etc. These provide people in the whole society to have less incentive to work, and thus the real GDP will not grow at a rapid rate. Since only if the real GDP is growing people will increase their investment. Countries with a lower Gini coefficient are less likely to have more investment in healthcare, and thus lower level of healthcare has been provided in these countries. On the other hand, in countries with a high
Gini coefficient, although with less income equality, income inequality is usually due to the policies set by these countries that do not aim to close the gap between the rich and the poor. For example, low unemployment benefits and transfer payment, less progressive income tax, etc. These policies could provide the whole society with more incentive to work and thus increase real GDP. As real GDP is increased, more money would be utilized as an investment, including healthcare. Thus higher level of health care could be provided in these countries.

Nevertheless, it is important to bear in mind that in a country with a higher Gini coefficient and a higher level of healthcare been provided, the inequality of access to healthcare could be as severe as the income inequality in that country. Although the average level of healthcare in these countries is high, they are majorly enjoyed by rich people who possess a higher level of income and wealth and the control of essential resources. The poor people cannot enjoy better healthcare, which means the increasing score of healthcare is the outcome of a process that the poor populations are averaged. As a result, the seemingly plausible shift in the healthcare system is indeed a truth that the rich benefit much from it, but the poor remain the same. In contrast, in those countries with lower Gini coefficient and relatively lower level of healthcare, although they might have lower average healthcare enjoyed, these are more likely to be more evenly distributed to each person in the society. Thus more people can obtain a basic requirement to the healthcare system.

\subsection{Evaluation}

Based on the proportion of each ability in the factor score, the research found that the correlation of income inequality, the outcome of healthcare, structure of healthcare, and process of healthcare.

In the data of outcome of healthcare including life expectancy and mortality from 1980 to 2017, life expectancy has increased gradually every year, but mortality keeps at a stable level. Gini coefficient stilly increments for 37 years. Using the factor analysis shows that the increase in the Gini coefficient will cause mortification of life expectancy and mortality. And this result corresponds to the research from Raj Chetty. In his essay, he states that higher income was associated with greater longevity in the United States between 2001 and 2014, and greater differences in life expectancy across income groups increased over time, which means the rich can enjoy a longer life and better healthcare. Still, the poor are limited in development very severely [19].

The second series is the number of beds and physicians, and these two are the fundamental part of healthcare. The physician's prescription, which must accompany the initial claim and supplementing documentation when required, must establish that a 
hospital bed is medically necessary. If the stated reason for the need for a hospital bed is the patient's condition requires positioning, the prescription or other documentation must describe the medical condition. For example, cardiac disease, chronic obstructive pulmonary disease, quadriplegia or paraplegia, and the severity and frequency of the condition's symptoms necessitates a hospital bed for positioning. Suppose the stated reason for requiring a hospital bed is the patient's condition requires special attachments. In that case, the prescription must describe the patient's condition and specify the attachments that require a hospital bed. The data of the structure of healthcare shows that as the statistics change, while Gini coefficient increments. And by calculating the proportion of healthcare structure through factor analysis, the result changes with the Gini coefficient. In spite, this result has contradicted the situation in Iran. That study indicated that the health centers had relatively equal distribution between Iran's provinces [20]. The data demonstrated that there is a relationship between income inequality and the structure of healthcare.

The last date is the vaccination rate of measles and DPT. A study in Japan has shown that socioeconomic status indicators, such as poverty, impact vaccine coverage. However, our study suggests that developing health policies for decreasing income inequality and increasing social capital might help achieve uniformly high vaccine coverage rates among children. According to this study, it claims that income influences vaccination, which is related to our research. As Gini coefficient develops, the number of measles and the DPT vaccination rate develops, resulting from factor analysis mortifies with Gini coefficient.

\section{CONCLUSION}

It is feasible to research the method of factor analysis to build an economic bond between the performance of healthcare and the income gap. In this article, the evaluation system is scientific and efficient, which makes a great devotion to analyzing the situation of healthcare in the U.S.A. from 1980-2017.

The survey has proved that a positive correlation exists between the healthcare score and the Gini coefficient in the specific period and location. The truth is that the rich can achieve more and better resources in the healthcare system as the Gini coefficient rises, which results in a huge improvement in aspects related to healthcare like the life expectancy and vaccination rate. On the contrary, the poor suffer seriously when the income disparity expands because they cannot get the ideal access to share economic development

To be more precise, the research claims that the increment of healthcare situation among the rich exceeds the increment of healthcare situation among the poor from 1980-2017 in the U.S. This phenomenon ultimately leads to the statistical result that the overall healthcare performance for the whole population in the country was enhanced as the Gini coefficient raises. However, the poor were crowded out of the improvement process, which is always ignored by the policymakers who merely care about the overall data. The result rings an alarm to all that more care should be given to the marginalized and poor populations, even though the whole situation seems prosperous. According to the result, the need to promote better and accessible healthcare in the poor is of great urgency.

\section{REFERENCES}

[1] Jong, F. (2018, August 20). Health inequalities and migrants: Accessing healthcare as a global human right. Retrieved May 08, 2021, from https://doi.org/10.1108/IJHRH-09-2018-076

[2] Mosadeghrad, A. (2014, July 26). Factors influencing healthcare service quality. Retrieved May 08, 2021, from

https://www.ncbi.nlm.nih.gov/pmc/articles/PMC41 22083/

[3] Kawachi, I., \& Kennedy, B. (1999, April). Income inequality and health: Pathways and mechanisms. Retrieved May 08, 2021, from https://www.ncbi.nlm.nih.gov/pmc/articles/PMC10 $88996 /$

[4] Healthcare. (n.d.). Retrieved May 08, 2021, from https://dictionary.cambridge.org/dictionary/english/ healthcare

[5] Chetty, R., Stepner, M., Abraham, S., Lin, S., Scuderi, B., Turner, N., . . Cutler, D. (2016, April 26). The Association between income and life expectancy in the United States, 2001-2014. Retrieved May 08, 2021, from https://www.ncbi.nlm.nih.gov/pmc/articles/PMC48 66586/

[6] Hoffmann, F., Lee, D. S., \& Lemieux, T. (2020). Growing Income Inequality in the United States and Other Advanced Economies. Journal of Economic Perspectives, 34, 52-78.

[7] James A. Macinko, L. (n.d.). Income inequality and Health: A critical review of the literature - James A. MACINKO, Leiyu SHI, Barbara STARFIELD, John T. Wulu, 2003. Retrieved May 08, 2021, from https://journals.sagepub.com/doi/abs/10.1177/1077 558703257169

[8] Yu, Zhe., \& Chen, Xue-feng.(2015, January 15). Analysis and experience of income distribution in the United States. Retrieved May 08, 2021, from https://kns.cnki.net/kcms/detail/detail.aspx?dbcode $=\mathrm{CJFD} \& \mathrm{dbname}=\mathrm{CJFDLAST} 2015 \&$ filename $=\mathrm{DJ}$ 
GL201505016\&v=\%25mmd2BjvaxuzxnxNzCQRI zXLDN\%25mmd2FNfnRp2E7skag\%25mmd2FDx CxRZ10G\%25mmd2FGBU5gxGO9xRLgPoRR5i

[9] Institute of Medicine (US) The National Roundtable on Health Care Quality. (1999, January 01). Measuring the quality of health care. Retrieved May 08, 2021, from https://www.ncbi.nlm.nih.gov/books/NBK230815/

[10] A simple way to measure health care outcomes. (2017, April 05). Retrieved May 08, 2021, from https://hbr.org/2016/12/a-simple-way-to-measurehealth-care-outcomes

[11]Claxton, G. (2019, August 21). Measuring the quality of healthcare in the U.S. Retrieved May 08, 2021, from https://www.healthsystemtracker.org/brief/measuri ng-the-quality-of-healthcare-in-the-u-s/

[12] Fiscella, K., \& Franks, P. (2000, April). Individual income, income inequality, health, and mortality: What are the relationships? Retrieved May 08, 2021, from

https://www.ncbi.nlm.nih.gov/pmc/articles/PMC10 89103/

[13] Schupbach,J.,Chandra, A.,Huckman,R.S.(2016, December 8). A simple way to measure health care outcomes. Retrieved May 08,2021, from https://hbr.org/2016/12/a-simple-way-to-measurehealth-care-outcomes

[14] Kawachi, I., \& Kennedy, B. (1999, April). Income inequality and health: Pathways and mechanisms. Retrieved May 08, 2021, from https://www.ncbi.nlm.nih.gov/pmc/articles/PMC10 88996/

[15] Bureau, U. (2021, April 04). Historical income tables: Income inequality. Retrieved May 08, 2021, from https://www.census.gov/data/tables/timeseries/demo/income-poverty/historical-incomeinequality.html

[16] Guo,Xing-hua. (2020, August 26). Empirical analysis of poverty alleviation performance evaluation in rural areas of A city based on factor analysis. Retrieved May 08, 2021, from https://kns.cnki.net/kcms/detail/detail.aspx?dbcode $=\mathrm{CJFD} \&$ dbname $=$ CJFDLAST2021\&filename $=\mathrm{JXJ}$ G202012022\&v=R2ikN81I51rMCznGbuzkCEJHTq zDdZQ90joS9dtoeAXZBvgBQsp9\%25mmd2F5U gcj53KY8L

[17] Guo,Xing-hua. (2020, August 26). Empirical analysis of poverty alleviation performance evaluation in rural areas of A city based on factor analysis. Retrieved May 08, 2021, from https://kns.cnki.net/kcms/detail/detail.aspx?dbcode $=$ CJFD\&dbname $=$ CJFDLAST2021\&filename $=$ JXJ G202012022\&v=R2ikN81I51rMCznGbuzkCEJHTq zDdZQ90joS9dtoeAXZBvgBQsp9\%25mmd2F5U gcj53KY8L

[18] Guo,Xing-hua. (2020, August 26). Empirical analysis of poverty alleviation performance evaluation in rural areas of A city based on factor analysis. Retrieved May 08, 2021, from https://kns.cnki.net/kcms/detail/detail.aspx?dbcode $=\mathrm{CJFD} \&$ dbname $=$ CJFDLAST2021 $\&$ filename $=\mathrm{JXJ}$ G202012022\&v=R2ikN81I51rMCznGbuzkCEJHTq zDdZQ90joS9dtoeAXZBvgBQsp9\%25mmd2F5U gcj53KY8L

[19] Chetty, R., Stepner, M., Abraham, S., Lin, S., Scuderi, B., Turner, N., . . . Cutler, D. (2016, April 26). The Association between income and life expectancy in the United States, 2001-2014. Retrieved May 08, 2021, from https://www.ncbi.nlm.nih.gov/pmc/articles/PMC48 66586/

[20] Ameryoun, A., Meskarpour-Amiri, M., DezfuliNejad, M., Khoddami-Vishteh, H., \& Tofighi, S. (2011). The assessment of inequality on geographical distribution of non-cardiac intensive care beds in iran. Retrieved May 08, 2021, from https://www.ncbi.nlm.nih.gov/pmc/articles/PMC34 81771/ 